\title{
A atual estrutura de preços de energia elétrica
}

\section{PETER GREINER}

Superintendente de Planejamento Tarifário e Mercado da ELETROPAULO. Engenheiro Civil pela Epuso, com poss-graduação em Admin istraçõo pela Fundação Getúlio Vargas, dirigiu as obras da usina de Chavantes e Paraibuna-Paraitinga e a área de Programação e Orçamento de Obras da Uselpa/CESP. Foi assessor da presidência da Construçōes e Comércio Camargo Correa para a área internacional.

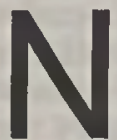
- momento que corre, falar do preço de um serviço público suscita, em boa parte dos leitores, idéias sobre custos exagerados, ineficiências e outras críticas do gênero.

$\mathrm{Na}$ verdade, o preço cobrado pela energia elétrica do Brasil é sensivelmente inferior aos preços vigentes na quase totalidade dos outros países, residindo o maior problema no baixo nivel de rendimento de uma grande parcela da população, em comparação com os palses mais desenvolvidos.

E justo dizer que o setor elétrico brasileiro apresenta uma concepção estrutural bastante aceitável, ainda que necesssite de algumas reformulações, e que os desajustes por que passa são de natureza passageira e plenamente superáveis, uma vez equacionados os fatores exógenos ao setor que se alinham como principais causas destes problemas.

Assim, o tema proposto se reveste de grande atualidade e importáncia fundamental nesta fase de ajustes inadiáveis. Após um perlodo de reestruturação, a partir da criação da ELETROBRÃS, há 20 anos, marcado por expressivos investimentos, nacionalização das concessionárias de capital estrangeiro, caracterizado, também, pelo uso extensivo de capitais de terceiros, o setor se defronta, no momento, com uma série crise financeira que vem a exigir significativas reformulações.

Ao mesmo tempo, a realidade politico-social presente vem colocando ao setor encargos adicionais, na medida em que se procura aliviar os custos dos servicos para as camadas sociais de menor renda e restabelecer tarifas incentivadas para alguns setores e atividades especificas, contribuindo, as correspondentes reduções de receita, para o aprofundamento dos problemas do setor.

Neste contexto, as polfticas a serem definidas devem se calcar no equilíbrio - mais adequado possivel, entre medidas de curto prazo, inadiáveis para o alivio dos problemas mais prementes, e aquelas básicas e duradouras, que visem assegurar à nação e a seus setores condi ções de um desenvolvimento seguro e sadio. E por este motivo que a parte conceitual da estrutura tarifária do setor de vem merecer uma atenção bastante cri. teriosa.

1. Características do serviço de eletricidade

Para fins de um claro entendimento dos princípios discutidos na tarifacão da energia elétrica é fundamental conceituar-se a natureza destes serviços.

O serviço de eletricidade pode ser entendido como indústria, fornecedora de um bem de utilidade pública: a energia elétrica.

Como indústria, deve estruturar sua produção e distribuição de forma autosustentável, com base nos preços cobrados aos consumidores pelos bens supridos. Por outro lado, considerar-se o serviço de fornecimento de energia elétrica como sendo de utilidade pública significa que ele deverá estar disponivel a todos que dele se queiram utilizar, mediante pagamento de um preço justo.

Excluindo-se o serviço de eletricidade da categoria do serviço público propriamente dito, elimina-se o custeio sis temático através dos recursos dos cofres, públicos, por conta da receita fiscal que onera toda a comunidade. Como corolá rio, a exigência da cobrança dos "servicos prestados" aos consumidores eliminaria a faculdade de favorecimento de uns em detrimento de outros.

Ao mesmo tempo, a obrigação da disponibilidade do servico, a um nfvel de qualidade e segurança compatível com sua importáncia, pressupõe um modelo econômico-financeiro e tarifário que permita o equilíbrio dessa indústria e viabilize a sua contínua expansão.
As caracteristicas básicas deste "servico de utilidade pública" são:

a) Necessidade de "monopólio ou privilégio por área de concessão", pois seria um desperdício e despropósito manter em duplicidade as redes de dis. tribuição elétrica. Por este motivo, cabe a órgãos do governo o "poder concedente da exploracão", vale dizer, a autoriza. cão do funcionamento de cada concessonária em sua área, bem como o esta. belecimento dos critérios de tarifação dos servicos e seu controle, em função da impossibilidade de opção por parte do consumidor e da inviabilidade de preços concorrenciais.

b) Simultaneidade entre produção e consumo da energia elétrica, que não pode ser estocada a não ser na forma de armazenamento d'água nos reservatórios, implicando no planejamento e capacitação antecipados do sistema para colocá-lo em condições de atender integralmente a demanda de pico e a energia requisitada pelos consumidores. 0 consumidor tem como natural e evidente a disponibilidade da energia: qualquer interrupção, independente de ser por necessidade de manutenção normal ou de racionamento grave, é interpretada co. mo falha do servico.

c) Os sistemas elétricos exigem alta capitalização e longos períodos de maturação dos projetos envolvidos: geração 7 a 10 anos e transmissão - 2 a 6 anos. Nestas condiç̃es, não sendo possível cobrar do consumidor atual o custo total antecipado dos investimentos relativos aos consumos futuros, o setor elétrico exige elevada capitalização para tais investimentos, abastecidos por capitais adicionais providos pelos acionistas, recursos de terceiros ou do governo, de acordo com a estrutura financeira adotada para o setor.

Resumindo, a tarifa da energia elé. trica deve:

- ser regulamentada e controlada pelo Poder Concedente ao qual cabe fiscalizar as empresas concessionárias;

- ser cobrada pelo servico, latu sen. su, abrangendo os custos de investimento e operação do sistema de geração, transmissão e distribuicão acrescidos da 
complexa infra-estrutura de apoio, gerência, manutenção, e etc.;

- integrar-se num modelo econômico-financeiro que viabilize a indispensável expansão dos sistemas para que a oferta de energia possa manter sua aderéncia à demanda nos diferentes pontos de consumo, vale dizer que deve compensar o custo do serviço prestado, incluida uma adequada remuneração do capital;

- dar tratamento equitativo aos consumidores que deveriam arcar integralmente com os custos envolvidos.

\section{Princípio da tarifaçåo pelo custo do serviço}

A partir da década de $1930 / 40$ a legislação do setor de energia elétrica (Código de Aguas) fixou como principio a tarifação da energia elétrica pelo "cus. to do serviço". Embora sua aplicação, ao nível das concessionárias, tivesse, ao longo do tempo, sofrido adaptação e agregação de normas e medidas, refletindo polfticas governamentais, o "custo do serviço" continua sendo a base referencial da fixação do nivel tarifário. Seu detalhamento pressupōe a prévia discussão dos conceitos envolvidos.

Classicamente se define o preço de um produto como seu custo de produção acrescido do lucro. Dar, a possivel inferência de que a energia elétrica, tarifada pelo "custo do serviço", seria fornecida apenas pelos custos operacionais, excluida qualquer parcela a título de lucro, entendimento simplista que inviabilizaria o setor elétrico, a menos que - governo provesse recursos para todos investimentos, a fundo perdido, por conta do contribuinte.

Conforme se viu, a atividade do setor elétrico envolve a aplicação de um determinado capital, em bens e instala. ções, nas condições estipuladas pelo Po. der Concedente, ao qual reverterão tais instalações, ao fim da concessão.

Não se justifica, no caso, uma com. pensação de risco, representando o lucro, tão somente, a remuneraçăo do capital investido pelo concessionário, uma espécie de empréstimo ao Poder Concedente, com reserva de administração.

Simplificadamente, o faturamento das concessionárias se compõe dos se. guintes itens:

$$
\begin{aligned}
& \text { I - Custos da Concessionária } \\
& \text { - Pessoal } \\
& \text { - Material, Serviços e Diversos } \\
& \text { - } \text { Quotas de Reintegração (De- } \\
& \text { preciação) }
\end{aligned}
$$

- Energia comprada

- Combustivel

- Diferença de câmbio

II - Remuneraçăo do investimento

10 a $12 \%$ /ano sobre o imobiliza-

do, destinado a:

- Dividendos sobre o Capital Próprio

- Custos dos Capitais de Tercei. ros

- Reinversões no sistema

III - Encargos do consumidor

- Quotas de Garantia (") - fundo de transferência de recursos entre concessionárias, para permitir a equalização tarifária.

- Conta de Consumo de Com. bustível - rateio do custo na geração térmica entre empresas interligadas.

- Quota de Reversão - fundo da União gerido pela ELE TROBRÁS.

(") constitui uma parcela aditiva (despesa), nas empresas de menores custos e uma negativa (receita), nas empresas de alto custo. Tratando-se de transferências, sua soma é nula para o conjunto de concessionárias do setor.

\section{IV - Carga tributária}

- Imposto Único Sobre Energia Elétrica - arrecadado pela União e redistribuldo conforme legislação própria.

- Empréstimo Compulsório para a ELETROBRAS.

A apuração dos "custos do serviço" $(1+11)$ é estritamente regulada pelo DNAEE - Departamento Nacional de Águas e Energia Elétrica, através de um detalhado Plano de Contas, associado a regras explicitas de contabilização.

São igualmente fixados pelo DNAEE os prazos de depreciação das instalações ( 33 anos para usinas hidráulicas, 25 anos para a rede de transmissão e distribuição e 20 anos para as usinas térmicas), além de critérios que limitam determinadas despesas: evolução do quadro de pessoal, cobertura dos juros de obras em andamento, etc... Por tudo isto se procura limitar e disciplinar a agregação de custos no interesse dos consumidores.

\section{Formação do preço final aos consu-} midores

Além dos custos e remuneração das empresas concessionárias são cobradas aos consumidores outras parcelas, entre as quais merecem destaque a Quota de Reversão, o Imposto Único sobre Ener. gia Elétrica e o Empréstimo Compulsório, compondo o preço final cobrado.

\section{Quota de Reversão}

Com a finalidade de constituir um fundo para reverter à União -o patrimônio das concessionárias de energia elétrica, no término do prazo das respectivas concessões, o Decreto $41.019 / 57$ criou as Quotas de Reversão ou Amortização.

Até 1971, estes recursos eram aplicados, pelas respectivas concessionárias, na ampliação de seus próprios sistemas, capitalizando juros anuais de $6 \%$ sobre o montante acumulado e contabilizado em nome da União.

A partir daquela data, as Quotas de Reversão, totalizando $3 \%$ anuais sobre o investimento das empresas, passaram a ser recolhidas a um Fundo de Rever. são, gerido pela ELETROBRÅS, que vem destinando tais recursos, cada vez mais, a suas subsidiárias, através de empréstimos a juros baixos.

A compra da LIGHT lúltima das grandes empresas privadas e estrangeiras do setor elétricol praticamente esgotou a razão original do Fundo de Reversão e, descaracterizando o seu objetivo inicial, ele se transformou, efetivamente, numa fonte de recursos para expansão do sistema.

Atualmente, seu cálculo está fixado em até $4 \%$ do Investimento Reversivel, segundo Decreto no 1.849/81.

Imposto Único sobre Energia Elétrica (IUEE) e Empréstimo Compulsório (EC)

O EC e o IUEE constituem obrigacões legais, de natureza distinta, calculadas sobre uma mesma base, denomina. da Tarifa Fiscal, uma tarifa média apu. rada para fins fiscais. O Empréstimo Compulsório é devido pelos consumidores industriais, com consumo acima de $2000 \mathrm{kWh} / \mathrm{mês}$, a uma taxa de $32,5 \%$ da Tarifa Fiscal. O Imposto Único sobre Energia Elétrica é aplicado aos consumidores comerciais, residenciais e industriais com consumo até 2000 $\mathrm{kWh} / \mathrm{mès}$, às taxas de $60 \%, 50 \%$ e $16 \%$, respectivamente.

É necessário lembrar a natureza dis. tinta destas incidências já que o Empréstimo Compulsório se destina diretamente à ELETROBRÁS, para devoluçăo após 20 anos de rentenção, descontos aplicáveis de até $98 \%$ a consumidores em condições especiais. 
Já o Imposto Único sobre Energia Elétrica não é passível de descontos e, repassado à União, é posteriormente destinado aos Municípios (10\%), Estados $(50 \%)$ e à própria União.

\section{Estrutura tarifária e descontos bási- cos vigentes}

Uma vez apurado o total do Custo do Serviço, projetado por todas as empresas e consolidado pelo DNAEE através do PLANTE - Planejamento de Tarifas de Energia Elétrica - cabe estabelecer as tarifas para os diversos grupos de consumidores, de forma a se ter a cobertura integral dos custos previstos.

Sobre uma estrutura básica de tarifas, condizentes à segmentação do mercado, aplicam-se, periodicamente (atualmente a cada três meses), elevações dos níveis tarifários para fazer frente à elevação dos custos, inevitáveis no presente regime inflacionário.

Idealmente, dever-se-ia cobrar ao consumidor a parcela real de sua participação no custo, em função do ponto e da tensão em que se contecta no sistema. Ainda que haja limitações na apuração dos custos a este $n$ Ivel de detalhe, o Poder Concedente criou uma estrutura tarifária que contempla os seguintes fatores:

- tensão de fornecimento: tarifas menores quanto mais elevadas a tensão e. por decorrência, o consumo, com menores investimentos da concessionária na rede;
- demanda: nos consumidores ligados em tensões mais elevadas a tarifa é binômia, cobrando-se uma tarifa de consumo, aplicado aos $\mathrm{kWh}$ consumido no mês (quantidade de energia) $e$ outra tarifa aplicada à demanda de potência do consumidor em $\mathrm{kW}$;

- políticas de incentivos: através de descontos aplicados a certos segmentos de consumidores e dos niveis mais baixos de consumo residencial, aplicados em cascata cumulativa, visando o tratamento equânime a consumidores da mesma classe.

A estrutura tarifária vigente a partir de 06/03/85 é a relativa a Figura 1.

A estes valores se acrescentam o Im. posto Único de Energia Elétrica ou Empréstimo Compulsório dependendo do tipo do consumidor.

\section{Incentivos e tarifas especiais}

Embora a legislação básica não presuponha a estatização obrigatória do setor elétrico, fato comprovado pela exis tência de um grande número de concessionárias privadas de distribuição, ainda que de porte reduzido, a política praticada conduziu à estatizaçăo quase total do setor, deixando as empresas distribuidoras sob o controle dos governos estaduais e concentrando a geração e transmissão, cada vez mais nas 4 "empresas regionais", subsidiárias da ELETROBRASS: CHESF, FURNAS, ELETRO SUL E ELETRONNORTE.
Por decorrència, vem-se ampliando o uso do setor como instrumento de implementação de políticas de governo, às vezes, em detrimento aos princípios da legislação básica do setor, destacando-se, resumidamente, os seguintes aspectos:

- equalização tarifária, pela qual as tarifas são uniformizadas para todo o território nacional, deixando de representar, ao nivel do consumidor, o resultado do custo efetivo da correspondente concessionária. Os "excessos ou insuficiências" de receita das empresas passam a ser compensados pelas transferências de recursos, através da Reserva Global de Garantia, processo que. se de um lado, viabiliza a expansão do serviço em regióes pioneir as com alto custo, de outro, introduz enormes ineficiências no sistema, na medida em que desestimula as concessionárias a minimizar os custos de seus serviços.

- sujeiçāo das tarifas a polltica de combate à inflação, conduzindo à redução do seu valor real, refletida pela queda da remuneração mínima legal (10 a $12 \%$ sobre o imobilizado em serviçol, para o nivel $6 \%$ a.a., que é insuficiente para cobrir o custo financeiro dos capitais de terceiros que representam mais de $60 \%$ dos investimentos totais, e cujo custo anual vem flutuando entre 12 a $16 \%$ a.a.;

- sujeição dos projetos de geração e transmissão à "polftica de rolagem da divida externa do pals" levando o setor a um crescente endividamento;

FIGURA 1

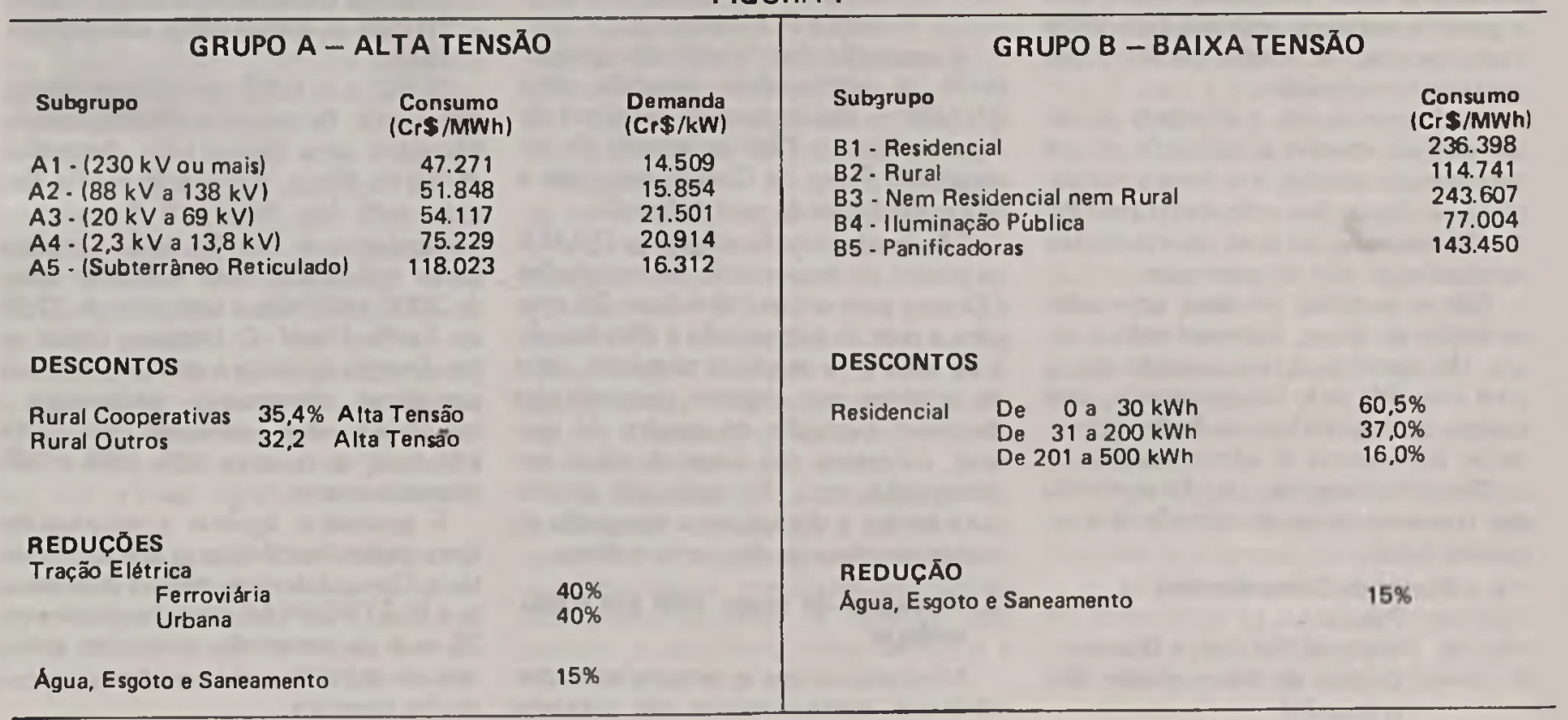


- priorização de projetos geopoliticos que não seriam contemplados, com a mesma urgência, pelo planejamento do próprio setor.

A conjugação desses fatores levou o setor elétrico, capacitado para um pro. cesso de desenvolvimento auto-sustentável, a enfrentar sérios problemas financeiros, acompanhados de uma expansão temporária de sua capacidade dispon 1 vel, ampliada, ainda, pela diminuição das taxas de expansão do mercado, devida ao perfodo recessivo de economia a partir de 1979

E neste contexto que devem ser entendidos uma série de subsídios tarifários adotados pelo governo federal, resumidos na seqüência, que, de forma geral, objetivaram:

- promover a absorção dos excedentes energéticos (melhor definidos como excedentes temporários de reserva de potêncial, permitindo, em parte, um adicional de receita;

- promover a substituição de energéticos importados:

- incentivar o setor industrial e a exportação.

\section{EGTD - Energia Garantida por Tempo Determinado}

Aplicável a consumidores em Alta Tensão, atendidos por sistemas in terligados, condicionado à substituiçăo de energia proveniente de derivados de petróleo, por meio de contratos firmados para 3.000 ou 6.000 horas anuais, ao custo de $\mathrm{Cr} \$ 20.370 / \mathrm{MWh}$ (28/12/84). reajustado conforme alteraçăo do óleo combustivel, contratos válidos até dez/ 86. Em 30/09/84 esgotou-se a disponibilidade do sistema para este fim. PORT. MME no 1.325 de $21 / 09 / 81$ e n:983 de 19/07/82.

PORT. DNAEE no 085 de 03/08/82 e no 132 de $30 / 12 / 82$

EPEX - Energia Excedente para a Produçåo de Bens de Exportaçăo

$\mathrm{Na}$ condiçăo de disponibilidade em sistemas interligados, para consumidores em Alta Tensăo que:

a) tenham dispêndio de energia elétri. ca maior a $3 \%$ sobre o valor das vendas;

b) apresentem previsåo de exportacăo de seus produtos para um perlodo de 12 meses:

c) optem por tarifas horo-sazonais:

d) efetuem o consumo fora do perío. do de ponta.

A tarifação para o consumo previsto corresponde a $1 / 6$ da tarifa fiscal, sem demanda - consumos e demandas excedentes pelas tarifas normais.

PORT. MME nọ 1.549 de 03/11/82 e

PORT. DNAEE no 107 de 22/11/84.

\section{ESBT - Energia Excedente para}

Substituiçăo de Petrōleo

Para consumidores em Baixa Tensão, em sistemas interligados, desde que não implique em alterações nos sistemas das concessionárias e que se caracterize uma unidade independente de consumo. Tarifado a $\mathrm{Cr} \$ 71.100 / \mathrm{MWh}$ para os primeiros $500 \mathrm{kWh}$ e $\mathrm{Cr} \$ 28.440$ para os restantes (08/11/84).

PORT. MME no 1.547 de 31/11/82 e

PORT. DNAEE nọ 116 de 15/12/82.

EFST - Energia Firme para Substituição

Para consumidor em Alta Tensão, in. clusive subterrânea, a partir de 01/01/85, no sistema interligado, desde que não tenha recebido energia em EGTD e ESBT, em contratos de 36 meses, firmáveis até $31 / 12 / 89$, energia interruptivel para equipamentos em substituição a derivados de petróleo. O consumo é tarifado a $85 \%$ da tarifa normal do subgrupo ou classe de consumidor.

PORT. MME no 1.267 de 14/09/84 e

PORT. DNAEE no 159 de 01/11/84.

\section{ETST - Energia Temporária para}

\section{Substituição}

Para consumidores em Alta Tensão, inclusive subterrănea, a partir de 01/01/ 85 , no sistema interligado, em substituição a derivados de petróleo, sujeito a restrições e interrupção, em função da disponibilidade, em contratos de no máximo 48 meses. Sem cobrança de demanda, a energia é faturada pelo maior valor da medição ou $80 \%$ da energia contratada com as seguintes tarifas (06/02/85):

A1 e A 2: Cr\$ 24.449/MWh

A3 : Cr\$27.162/MWh

A4 e A5: Cr\$ 28.876/MWh

PORT. MME no 1.267 de 14/09/84 e

PORT. DNAEE n? 160 de 01/11/84.

\section{Irrigação (Descontos)}

a) consumidores rurais do sistema interligado, para fins de irrigação, serão dados os seguintes descontos na Alta e Baixa Tensão:

Grupo A: $50 \%$ sobre tarifa demanda com descontos.
Grupo B: $35 \%$ sobre tarifa Subgrupo B2.

b) Cooperativas:

Grupo A: $50 \%$ na tarifa de demanda agregada de irrigação.

Grupo B: $59 \%$ na tarifa do consumo agregado de irrigação.

PORT. DNAEE n? 053 de 05/04/84.

\section{BIBLIOGRAFIA}

- Eng? Mauro Thibau - Polftica Tarifária nos Servicos de Eletricidade.

- Enoo Mário Penna Behring - Comissão da Cámara dos Deputados Set/83

- Eng? Paulo Procopiak Aguiar - Tarifa Única: Fundamentos e Avaliaç̃o 20/01/84.

- Boterim Tarifário de Fornecimento - Portaria n: 040 de 05/03/85 ELETROPAULO. 